\title{
Becoming Strong: Theorizing as Morally Oriented
}

\author{
Rodney Evans \\ Past Graduate \\ Department of Educational Administration \\ University of Calgary
}

When I began my graduate studies in education at The University of Alberta in 1981, phenomenology was altogether an unknown word to me. Likewise, the term pedagogy was rather a vague and slightly esoteric term which had little currency in the mainstream journals of education and seldom entered into the discourse of professional educators. As an aspiring educational administrator and beginning graduate student I had no reason to doubt that the way things were was the way things were supposed to be.

About that time the Human Science Circle at the University of Alberta was being formed under the guidance of Max van Manen. Earlier I had taken his course on Pedagogical Theorizing and it was here that I encountered for the first time the works of the great philosopher-pedagogues. This was a revelation. Here was a body of thought that wanted to understand pedagogy and the nature of pedagogical relations vastly differently from anything I had previously encountered in the research literature. The very practical question at the time was how to reconcile this work-and the slowly emerging sensibilities that were growing out of the study of this work-with what I perceived to be requirements and expectations of an erstwhile doctoral student in educational administration. The upshot was to be a dissertation entitled Ministrative Insight: Educational Administration as Pedagogic Practice.

Today as I teach as an assistant professor in the Department of Educational Policy \& Administrative Studies at the University of Calgary I continue to be preoccupied with many of the same questions but now especially with the question how the "two solitudes" of education and administration can be reunited in more educative and mutually sustaining ways. This is the thrust of my current research program. It will likely occupy me for quite some time. In this endeavor the past and present pages of Phenomenology and Pedagogy continue to be a vital source of insight and inspiration.

\section{The Impulse to be Strong}

The impulse to be strong in our orientation to practice is an impulse that underwrites the various approaches to educational theorizing in their diverse and multiple forms. Yet it is undeniable that today the impulse to be strong is one that encounters considerable resistance from many quarters-most notably from educational theorists, policy makers, and others who see the educative task as serving more limited ends and more restrained purposes. Today the issue of strength and the question of what counts as a strong orientation to practice is much more likely to be

Phenomenology + Pedagogy Volume 91991 


\section{University of Alberta}

formulated as part of a program of technical competence than it is likely to be read as a form of theorizing that is morally oriented in its course. Still, this resistance by no means denies the deep need that exists to establish a strong relation to practice, and indeed the impulse to be strong in one's orientation to practice remains a fundamentally inescapable impulse.

The main question and pedagogic challenge, then, becomes the issue of how it might be possible to engage in various types of pedagogic practices that might help foster and encourage the impulse to be strong in our orientation to practice. Although other means and other methods may be possible, in the narrative text that follows the idea of a strong reading is put forward as one way in which such practices could be strengthened. But now a caveat. This article works not at the level of abstract theory as if the practices themselves could be strengthened by more abstract talk about them, or as if we did not already have a surfeit of meta-talk that leaves us almost exactly where we started from. Rather, the narrative proceeds reflexively insofar as the text aims to exemplify in its own very way or mode of proceeding precisely those pedagogic principles on which it depends and which it therefore aims to recommend. What this article does not promise is any kind of discourse on (from the Latin discursus, dis-apart + cursus-a running, cursus being the past tense of the [Latin] verb currere, to run) the topic of strong readings. Precisely what makes a strong reading strong is its living character as conversation, as speech. This can be tentatively formulated as follows.

What makes a strong reading strong is its self-illuminating (reflexive) character in which its own very speaking is an instance of those very precepts and principles it wishes to recommend.

Or again:

What makes a strong reading strong is its reflexive character as principled speech.

\section{Strengthening a Pedagogic Text}

In the textual narrative that follows, I like to explore the possibilities that exist for a strong reading of a school principal's pedagogic text. The text in question is not especially significant except insofar as it furnishes the opportunity for pedagogic reflection (a strong reading) of the events it describes. I let the principal tell his own story.

Last night I received a phone call at home from my guidance counselor who was here finishing up some work quite late. Apparently one of our students and one of his friends were here because we have a computer club that operates until 4:30 p.m. Well, our caretaker caught them jamming a piece of wood in the lock of a back door of the school, and they [caretaker and school counselor] made the assumption that the wood was being used to prevent the door from locking, presumably so these kids could get back into the school later. One of the kids took off but the other kid didn't and the 
only person in the school with any degree of authority was the guidance counselor. The boy would not tell who the other boy was and was very arrogant, insolent and rude with the caretaker and the guidance counselor and so they left and so I had to see the boy this morning.

Every principal and every educator knows of situations when things go badly, when the educational goal one is aiming for is missed or somehow thwarted and when, as a result, one's patience and tolerance are sorely tested. These are the moments we least like to talk about, probably because we feel they reflect badly either on our planning skills or on our management strategies, or on some or other aspect of our educational selves. We tend to feel that with greater foresight or with improved social-psychological knowledge such events could and indeed should have been avoided. And yet by the same token such events (like the one described above) have a way of disrupting the best laid plans and most carefully organized instructional sequences with an obstinacy and, at times, a frequency that leaves even the most meticulous administrator breathless.

Like it or not, this is the hard reality we face as educators. In the story that follows a school principal describes just such a situation. The situation itself is neither especially good nor especially bad, not entirely usual nor yet entirely unusual, in the grand scheme of things it is neither especially dramatic, nor especially mundane. In all likelihood it is probably fairly typical of the kind of situation school principals find themselves faced with (and having to do something about) day in and day out. And many (probably most) other educators would no doubt find the situation as difficult and as challenging as the principal in the story. Let us listen as the principal tells his story. But in listening to the story we also want to try to hear what the principal is saying and in fact recommending-not just about the boy, his crime (intended or committed) and its aftermathbut also about the nature of education, the values that underlie it, the reasons for engaging in it, the purposes that drive it, and so forth.

Anyway here was a 14-year-old, grade 9 boy telling me in my office that it isn't his responsibility if someone wrecks the school. He said he told his buddy not to jam the lock, and that he was trying to remove it when the caretaker saw him. So I said: "Who is this kid so we can talk to him," and he said: "I can't tell you that because he's my friend." But I said: "What if he'd come back into the school and wrecked it, you'd have been accountable and responsible." He said: "It's not my responsibility if he wrecked the school." I said: "But your parents are paying taxes, and if there's vandalism in the school we have to spend money to repair it and that means less books for the school." And he said: "Well that must be your responsibility because it's not mine." And I said: "Are you telling me that if you saw someone climbing into a house about to set fire to it and he was a friend of yours, you wouldn't tell on him?" He says: "Yeah, that'd probably be right." Then I said: "What do you consider your role as a citizen to be?" And he said: "To do the things I like and enjoy and mind my own business and let other people do their thing." 


\section{University of Alberta}

This is a striking conversation in many ways. At the prima facie level it would be difficult not to notice the rather undialogic, tension-ridden nature of the exchanges between the principal and the 14-year-old. Certainly, there seems to be little in the way of real conversation here. And the reason is not so hard to find. Both parties to the conversation bring to the encounter different sets of assumptions, interpretive schemas, value frameworks and so forth. These differences give rise to different ways of defining the situation and therefore to ways of responding to it. These need to be examined a little more closely.

\section{From the Side of the Principal}

From the side of the principal the issue is fairly clear cut. Here is a student who appears to have no respect for public or private property and who when quizzed about it displays disturbing tendencies. But there is no doubt the principal takes the boy's behavior seriously. As a consequence, the principal interprets his task as that of trying to inculcate a certain respect for social and community values that, after all, are part and parcel of the socializing mission of the school.

Seen in this light there is a definite pedagogic purpose behind the principal's questions. Certainly the questions are intended to point the way to a heightened sense of personal and social responsibility on the part of the 14-year-old. Naturally schools should aim in this direction. So the questions in this way are good questions. And yet they backfire; they do not hit home. The boy replies in a way which discloses his unresponsiveness to this line of questioning. The principal for his part immediately judges the boy's unresponsive nature as evidence of the child's inadequate socialization. In his mind a serious situation exists.

This is really frightening to me. I just couldn't believe what I was hearing. So I placed him under a five day suspension. The father is employed as a chef of some kind and the mother is a private nurse. I phoned several times and couldn't get anybody at home, but I've got to have the parents in because this kid is showing very dangerous signs, very dangerous signs. You know, the kind of kid who wouldn't hesitate to kick a door down, or a window. And I haven't checked my car but maybe all my tires are flat by now. But when a kid outright tells you he doesn't care what happens to public property, to his house or your house--and he's a nice looking kid which kinda surprised me. But just brutal! To me this kid has just got some kind of misconcept of basic right and wrong. At least that's my first impression. That's why I suspended him so he could do some thinking about this thing.

What is interesting and quite significant in this situation is the way the principal formulates a sense of this young person as someone who is basically unprincipled, as someone who would not hesitate to kick down a door or smash windows if the need arose. While there is probably some element of overstatement in the way the principal recounts the details of the situation there is no doubt that he takes the boy's behavior seriously. The principal judges this boy to be dangerous because on the face of it he 
appears to be insufficiently socialized to the norms and values of the community. He is judged dangerous because he does not value what the principal, as guardian of the public good, believes he ought to value. And what he ought to value (in the eyes of the principal) is the importance of treating public and private property with respect, abiding by accepted community standards, and where necessary relegating other values (being loyal to one's friend, for instance) to a subordinate position.

Clearly the issue of responsibility is an important one for schools, and so the principal is quite right in wanting to give the child a nudge in that direction. Bit by bit, children need help to see that far from a simple notion, the issue of responsibility is an inordinately complex affair. Beyond the concrete immediacy of the practical situation that confronts the principal is a set of related issues concerning the nature of adult maturity, the meaning of competent citizenship, the requirements of community living, and so forth, that forms a context of meaning in which the situation can and should be understood. But for our purposes as educators-concerned more with the living moment and its here-andnow character-there is also (and more primordially) the living reality of the present encounter in all its physicality and concreteness in which an adult encounters a non-adult in a compelling and demanding way. But to describe this situation as an encounter is to recognize it as the site of the meeting of two quite different sets of values and interpretive understandings. On the one hand those of the principal, and on the other those of the boy.

\section{From the Side of the Boy}

As educators we can see how the situation might be more complex than the principal's representation of events might suggest. At a minimum there is the issue of what ought to be valued in this case. What do we say, for example, about a child who refuses to tell on his friend? Is this the act of a dangerous and unprincipled child? So while the principal orients to the value of property, social and community norms, and so forth, the boy, it seems, orients to a value of a different kind. What the boy stands for in a sense is the value of friendship. While the principal draws his sense of value from the object world around him, and while he bases his conception of competent citizenship in a necessary respect for the property rights of others, the boy it seems bases his conception of right action in a concern for the value of human relations. And although he does not say as much in words, we can perhaps see in the boy's response a quality of personal loyalty, individual faithfulness to a friend, refusal to betray a pal, and so forth.

The pedagogic point I want to dwell on for a moment is not to insist on the superiority of one value, treating public and private property with due care and respect, over another value, being loyal to one's friend, but rather to see that both values have their place in the overall scheme of things. As is true of most if not all educational situations, it is seldom the 


\section{University of Alberta}

case that truth in the sense of right action ever lies completely on one side or the other. But neither is it the case that the situation is wide open in the sense that any kind of response will do. This is precisely the point of a strong reading of this situation-to see in what way the principal's practice conforms to a more pedagogic sense of what this situation calls for. This raises an interesting question: What is called for in this situation?

To address this question we need to focus first on the young person in the story and in particular on his refusal to reveal the identity of his friend. Much could be said about the moral merits of this refusal. Still, it is likely true that the boy in question is lacking in a wider sense of social and civic responsibility beyond the sphere of the immediately personal. He needs help to be able to see the claims that membership in a social collectivity make of us. This is the pedagogic admonition in this case. Recognizing the legitimacy, the desirability even, of the child's value as one worth holding, the principal is challenged to deepen and complexify the child's thinking such that the child can come to his own realization of the importance of treating public and private property with respect. Maybe too there is an issue of friendship here. Maybe a real friend is someone who tries to convince his pal to come clean when he is in the wrong.

The point is that these are all pedagogic possibilities for the principal. It should not be so surprising that the child places the living relation of friendship, as an experiential claim, above the more remote concept of abiding by various social and community norms that are in any case highly abstract and largely theoretical claims. Far from seeing this child as valueless and as someone who is in a fundamental sense ungovernable, part of the challenge of the principal is to formulate an image of this young person as someone whose values, though ultimately somewhat narrow and incomplete from a fully adult point of view, are nonetheless well grounded in a sense of duty to one's friend, loyalty, steadfastness, and so forth. As educators, we may want to notice too the origin of the boy's value orientation in the realm of the geist or spirit as opposed to the principal's value orientation centered as it is in the object world of things. This too is pedagogically significant.

The point about doing a strong reading is not simply that we wish to map the value topography of the landscape as if we were engaged in nothing more than inventory work on the different types of values and the nature of their grounding. Already that would betray a certain kind of interest in the nature of value that would be far removed indeed from a pedagogic interest. A pedagogic interest in the question of value is already an interested interest in the sense that whether we like it or not we always find ourselves inter-esse (in the midst of things). Thus there is no possibility in this research of a neutral (descriptive) reading of the principal's stories. Doing a strong reading is from the beginning a committed reading in the sense that one is ethically involved in the stories. This is 
different from a technical reading of the texts for which one does remain ethically neutral and methodologically distant. But this is taking us too far afield and away from the business at hand.

I want to turn now to a somewhat closer reading of the third and final segment of the principal's story, which at the same time as it contains by far the clearest and most explicit statement of the principal's theory of administration also contains some of its most problematic features.

I had an experience in another school where I had to repair $\$ 900$ worth of locks, 'cause kids jammed them with gum and that money came out of a fund which we had to buy uniforms and other things for the kids. So I'm not comfortable with this kid. If you were my neighbor and I went out of town and you see someone breaking into my house-that's a wrong behavior to expect from people in a society-and I expect that whether it's your friend or your son, for you to do something about it. So here's a kid who's 14 years old and in four years is going to be of the age of consent. Scary! You see, to me the school is a part of the socialization process. It's part and parcel of the expectations of the community. The school should extend and reinforce the community expectations and the home expectations. Parents have a right to expect this. It's what schools are for.

The examples the principal brings forward to justify his action in suspending the boy are in many ways revealing. The incident with the locks, and the hypothesized break-and-enter situation once again reveal the principal's concern for the object world as that domain of thought that serves to supply the principal with his source for value. While it is undeniable that the principal has a good deal of commonsense wisdom on his side ("of course schools should take a stand against such things!") and although he can lay claim to being realistic and practical and acting for the public good we would still have to ask, as educators, whether a value orientation anchored firmly in the object world can sustain anything beyond the most impoverished and emaciated forms of pedagogic thought and practice. This is what a strong reading of the principal's text would want to make clear. A strong reading would want to take issue with the principal's preoccupation with the object world as an adequate source for pedagogic values. Here again we would want to recall the child's value orientation grounded as it is not in the object world, but in the living and experientially real world of spirit in which one can experience the claims that having (and being) a friend makes of one. Or, to put it the other way round, what would we say of someone for whom such claims did not exist, who could not feel (was incapable of feeling) the pulls and tugs-in short the claims - that friendship makes on us? Would this not be a matter of much greater pedagogic concern?

But let us return more matter-of-factly to the text itself. From the discourse of this principal it seems difficult if not impossible to do anything constructive for this boy. I have already mentioned that the principal can (and indeed does) claim to be acting for the public good, and 


\section{University of Alberta}

that he is simply being realistic in his assessment and treatment of this child. And in a way he does just this in his suggestion that the task of the school is to extend and reinforce community expectations and the expectations of the home. But there is a bigger and more important point here. It has to do with the relation between school and home on the one hand, and school and world on the other.

We need to remind ourselves as educators that (the idea of) school is not simply identical with the notion of home any more than it is precisely the community writ small. Already this would be a major misunderstanding of the place and ontological location of school. In being neither home nor community, it (the idea of school) occupies a middle ground of its own. It is a place where we introduce children to the world, but it is not the world. This is what a strong reading of this situation would want to make clear. We do the idea of school an injustice when we think of it as simply a microcosm of the real world. This being the case we cannot base our actions or our conceptions of what is appropriate or inappropriate behavior on the norms and values that inform the conduct of the real world. To do so would be pedagogically inappropriate. It would be to deny the very idea of school its internal validity, a validity which, as Arendt (1954) has pointed out, cannot be claimed and should not be sought in the general world of adults.

Many consequences flow from this with implications for the present situation. For now all I wish to point out is that to be more fully a principal would be to recognize the special place of school as occupying a middle ground of its own located somewhere between home and the world. It would mean that what goes on in schools draws its logic and its justification primarily from its place between and only secondarily from the location of home on the one side, or world on the other. This places the school principal in a special position. To be a principal in a strong sense is to understand how the deep structure of educational activity can only be arrived at through an attentiveness to childhood and the meaning and nature of pedagogy itself. Seen in this light we see how misplaced are all those analogies that try to link school and world, and how the norms and standards that govern behavior in the adult world cannot automatically be used as a resource to structure the substance and nature of educational activities.

So while the principal needs to hold to his adult value as one worth holding, we see also the requirement for him to recognize the young boy before him as a child in the process of becoming. This, in a sense, is why we have schools, so that children who are not yet adults can try on the values of the adult world in a sympathetic and forebearing way. Not to see schools in this way is, in essence, not to see children, or at least to see children as no more than small adults. For educators it is important to see the problematic character of this view and the antipedagogic vision that informs it. 
Doing a strong reading of this or any other situation is therefore an effort to see-at the level of actual practice-what it is that underlies our task as educators. There is, clearly, an assumption here that being an educator, in this case a school principal, does not mean just anything any more than it means what we might like or subjectively intend it to mean. Objectivist and subjectivist approaches that begin by ignoring or overlooking the deep meaning that inheres in the structure of practice tend to deny the very possibility of meanings other than those we ourselves create and allow. Although we cannot speak of certainty here or be in any way definitive about things, neither is it the case that nothing exists or that there are no meanings other than those we so graciously choose to bestow on an otherwise empty landscape. The very possibility of a strong reading points to the existence of something that gives us the wherewithal for a reading of any kind whatsoever. Put differently, we may say that interpretation always requires an object, that is, we never simply interpret, but always that we interpret in terms of something else, in terms of something other. It is precisely the existence of this other that makes interpretation a necessary, inevitable, and ultimately inescapable activity. It is also what enables us to speak at all meaningfully of the possibility of misinterpretation.

\section{Fostering Pedagogic Competence: Seeing What is Needed}

I now describe the practical pedagogic competencies arising out of the strong reading of the principal's story in order to give a sense of the theory-practice implications arising out of work of this kind. The first relates to the place and function of punishment as a pedagogic phenomenon in the overall upbringing of a child.

In the principal's story we read how the boy has been caught red-handed in the act of jamming a door lock with the apparent intention of getting into the school later in the day. The experience of being caught (as Sartre, 1956, has unforgettably shown) now fundamentally alters the modality of the way in which people, events, relationships, and so forth are experienced. Now the world and everything in it are experienced from the point of view of the one-who-has-been-caught. How is this pedagogically significant? A pedagogically sensitive adult realizes that it is likely that a certain shamefulness, a certain consciousness of having done wrong now permeates the child's experiencing of the world. The experiencing ego now encounters the world on distinctly different terms. Psychologically, this places the one-who-has-been-caught in a position of extreme vulnerability; points of contact between self and world are stretched thin, even to the breaking point; relationships that were firmly grounded in respect, mutuality and so forth, become tentative and fragile. Defending the exposed ego now becomes the mainspring of action.

The point for pedagogy is to understand how far this altered state of consciousness acts as an impediment for the restoration of pedagogic relations. A pedagogically sensitive adult understands the importance of 


\section{University of Alberta}

assisting the child to regain the earlier state of consciousness in order for the world to be once again encountered on its own terms. And here we approach for the first time what we might regard as the pedagogic justification for punishing. Here punishment has a certain pedagogic value in providing for a form of atonement by means of which the child is provided a means of paying off debts. It is a way of "getting out from under" a means by which the full potency of pedagogic relations can be restored. From the child's point of view it is extremely important that such opportunities be granted so that he not be condemned to labor indefinitely under the educator's bad opinion of him. This is certainly part of the larger pedagogic competence that is implied by the principal's story-namely to see that when punishing is called for, what calls for punishment is a pedagogic understanding of the child's need to return to an earlier state of consciousness characterized by a free and open relation with the world. It need hardly be said that this is different from punishing for retributive reasons, to demonstrate a power relation or to convince a child of the wrongfulness of his or her actions. We see also that it is not the fact of punishment that counts so much as the experiential quality or subjective meaning of the punishment experience itself that is the truly decisive factor.

It is in consideration of such situations that we begin to sense how the image of the principal as authoritative allocator of value (in the principal's story, having to decide on the value to be placed on the moral imperative of being loyal to one's friend over against the value to be placed on treating public property with due care and respect) falls short of the pedagogic meaning and significance of the principal's educative task. It is not yet enough for the principal to be no more than a distributor of value or moral umpire no matter how ethically sincere and well intentioned the motives that underlie such acts may be. As an educator, more is required and expected. A principal's practice, after all, is not a legal practice any more than it is primarily a bureaucratic or managerial practice, so much as it is a pedagogic practice, and so more is involved than a mere judicial pronouncement of which value shall reign supreme.

\section{Educational Administration as a Normative Practice}

Despite modern attempts to turn teaching into a largely technical activity, education is from the first a normative practice. Schools have always been involved in questions dealing with the pedagogic life of children. And as van Manen (1990) has pointed out, fundamentally all curriculum practices involve questions of worth whileness, goodness, appropriateness, and so forth. Teachers, especially principals, are often thought of as people who can be relied on to take a stand on various moral and ethical questions, especially those that bear on the pedagogic life of the child. Education in its broadest sense has long maintained its right to participate in the process of conscientization, the forming of an individual in the full (moral) sense of the word. The notion of punishment 
and of punishing received its justification from a vision of education that saw itself as intimately involved with the moral life of the child, that is, with the process of character formation. It was in this sense that schools could claim to be a preparation for life not in the narrower vocational sense that now prevails, but in the sense of preparing a child to stand in life where standing in life implies a readiness to celebrate life's joys as well as a preparedness to withstand the vicissitudes that human living inevitably implies. In this sense the principal's practical definition of educational administration as a morally oriented practice is by no means misplaced. We may even wonder whether the principal has grasped something basic to the practice that has been lost to more modern (theory based) forms of educational administration.

So part of the competence that is needed to be a school principal involves the realization that education in its deeper sense is a fundamentally moral endeavor. Schools are not just places where children learn math and science, for example. More fundamentally they are places where children learn to become someone, where becoming someone now implies what has long been thought of as a process of personal and moral growth: a process of conscientization in the full sense of the word. The real issue, however, turns on the question of how to involve children in a process of personal and moral growth. How is this kind of growth possible? Part of the competence of being a principal is the posing of this question, but part lies also in the way in which a school principal attempts to answer it.

These questions are, of course, among the most difficult that could be raised. And yet such questions are central to any adequate formulation of administrative practice in schools. What special competence is required here? By what manner or means can an educator, especially a principal, contribute to the moral growth of a child? In what follows I simply wish to offer some general considerations that surround the asking of this question.

\section{Sponsoring Personal Growth}

If the moral growth we seek is to be a real phenomenon and not merely a show or pretense of growth then its source must be located deep within the psychic consciousness of the child. It cannot be an external attachment of this or that particular value from the outside as through some process of persuasion or, worse, a coercive process of some kind. In the present case of the boy who broke into the school, it seems that the boy needs to be brought to a situation where he can come to see for himself the value inherent in preserving things held in common as a value worth preserving. But to be morally valuable the value must be freely chosen. It must be freely entered into as the conscious act of a free agent freely choosing.

We come close here to an essential part of an educative (pedagogic) relation: namely, for the principal to see that the child must have avail- 


\section{University of Alberta}

able to him the social-psychological space to arrive at his own moral conclusion and that the educator must not rob the child of the opportunity of coming to a stand even if the place of the stand is other than that the educator would himself have chosen. In what position does this place the educator? Does this mean that the educator must stand idly by in the face of whatever moral direction the child seems headed? Of course, the educator is no mere moral spectator but actively seeks to engage the child in a process of moral reflection not simply so the child may become clear about the consequences of holding to this or that value, but with the active intent that the child will take up the desired (desirable) value. So the educator as pedagogue tries to steer the child in a particular direction but always in the knowledge that the choice of final destination remains with the child. It is this realization (I will call it this competence), that saves education from degenerating into a species of indoctrination.

But the principal's practice in this situation implies a further competence that relates to the idea that moral growth cannot be compelled, cannot be forced. If it is to occur at all it must arise naturally and of its own necessity from within the recesses of human consciousness. It cannot be contrived. It is just this feature of moral growth that gives rise to a necessary element of risk that attaches to all truly educative activities. There is no possibility here that the educator can guarantee the success of his or her efforts. Because the child must be free to choose there remains always the possibility that the child may choose despite, or even in the face of, the intentions and wishes of the educator. The educator may fail. This possibility is what weighs so heavily in all educational activity. For the risk of failure, as Bollnow (1971) has pointed out, is not merely an ancillary or incidental feature of education but belongs to it as part of its essential structure. It is just this aspect of educational work that cannot be planned or calculated away but remains nevertheless a risk which the educator (in this case the school principal) must be willing to embrace. The educator's willingness to do so we can call a certain kind of pedagogic competence.

\section{The Impulse to be Strong: Again}

Doing a strong reading of this or any other situation is thus the effort to see-at the level of actual practice-what it is that fundamentally grounds and authorizes our pedagogic acts as teachers, principals, (and other educators) in our everyday relations with children. And certainly there is at work throughout the strong reading the realization that something grounds and authorizes that relation (even though that something more often manifests itself as a nonpresence than as a presence). Far from a neutral or merely descriptive (explanatory) activity, the task of educational theorizing should thus be seen as that activity (that practice) that aims to sponsor a certain openness and receptivity to this something. The practical question then becomes: What possibilities exist for developing a strong orientation (relation to) practice? Or, what 
amounts to the same thing: What stands in the way of giving rein to the impulse to be strong?

Today this question stands in need of strenuous contemplation. In retrospect it is amazing how easily the question is brushed aside in favor of ideological disputes and paradigmatic skirmishes of one kind or another. Could it be that in our quest for self-sufficiency and methodological certainty we no longer quite know what is the task of theorizing? Becoming strong [in our orientation to practice] has been conventionally translated as becoming effective, becoming efficient. But such a translation is actually a mistranslation. The twin peaks of effectiveness and efficiency (on which so much modern faith is lavished) should not be confused with strength. Ironically, we find ourselves in the paradoxical situation of having to reconstruct the notion of strength out of a much depleted sense of what counts as a strong approach to practice.

\section{References}

Arendt, H. (1954). Between past and future. New York: Penguin.

Bollnow, O.F. (1971). Risk and failure in education. Existential Phenomenology, 6(3), 520-535.

Sartre, J.-P. (1956). Being and nothingness. New York: Washington Square.

Van Manen, M. (1990). Researching lived experience: Human science for an action sensitive pedagogy. London, On: Althouse Press; New York: SUNY Press. 